\title{
The Ethics of Exclusion in Infertility Care
}

\section{Richard F. Storrow}

School of Law, City University of New York, 65-21 Main St., Flushing, NY 11367, USA

\begin{abstract}
This commentary examines the applicability of medical ethics principles to a discrimination case decided by the California Supreme Court. It compares the potential-patient provisions and the ongoing physician-patient relationship provisions of the American Medical Association's Code of Medical Ethics to explain why several medical associations were in conflict about how medical ethics should apply to the case. The commentary argues for a stronger expression of commitment to non-discrimination in the treatment of patients in ongoing physician-patient relationships.
\end{abstract}

Do codes of medical ethics permit religious doctors to discriminate against their patients based on race, religion, sexual orientation or marital status? In recent controversies over religious refusals to dispense emergency contraception, both sides respond with a resounding no. The consensus is that a religious physician may refuse a specific treatment to all patients but may not choose between patients based on characteristics protected by law against discrimination.

The recent case of Benitez v. North Coast Women's Care Group [1] calls this consensus into question. In Benitez, a group of infertility physicians argued that their sincere religious convictions permitted them to treat only infertile women in heterosexual marriages. When a lesbian patient they had been treating with low-level fertility procedures required intra-uterine insemination, the clinic terminated the relationship and referred her to another clinic for treatment that was ultimately successful.

In most jurisdictions, refusing treatment in this manner would be perfectly legal, since laws prohibiting sexual orientation and marital status discrimination are relatively rare. But in California sexual orientation discrimination is illegal. Did their sincere religious beliefs exempt the North Coast physicians from the law? The Supreme Court of California ruled no in a unanimous decision.

Several medical associations filed briefs on both sides of the dispute, raising arguments based on medical ethics. One group of associations argued that medical ethics principles permit doctors to refuse to treat a patient for religious reasons as long as they provide an immediate and effective referral to another physician. This refuse-andrefer mechanism, it was said, renders ethical what would otherwise be unlawful discrimination. Other medical associations asserted that even religiously motivated discrimination that targets sexual orientation is a violation of medical ethics. The California Medical Association, reflecting the general confusion, initially supported North Coast but in the midst of the litigation withdrew its original brief and submitted a revised one that favored Benitez. The CMA had at first reasoned that religiously motivated discrimination in medicine requires balancing the interests of the physician and the patient. Its revised position was that "the CMA would never support the claim that a physician's religious freedom authorizes discrimination based on race, nationality or sexual orientation."

An examination of medical ethics principles explains why doctors cannot agree whether medical ethics permits physicans to discriminate on the basis of their religious beliefs. The American Medical Association developed its Code of Medical Ethics primarily for the benefit of patients. Opinions 9.12 and 10.05, which elaborate upon Principle VI, contain a prominent prohibition on discrimination against potential patients. The code would permit a religious physician to refuse to offer a potential patient a particular procedure as long as the objection was to the procedure itself and not to some legally protected status of the potential patient. Neither of these principles applies to a case like Benitez, since Benitez was already North Coast's patient at the time it referred her elsewhere. Furthermore, North Coast had no general religious objection to intra-uterine insemination as a procedure. It objected to providing IUI to Benitez in particular.

Since Benitez was in an ongoing physician-patient relationship at the time her cause of action arose, North Coast's discontinuing her treatment might be considered neglect or even abandonment [2]. In this connection, Opinions 10.01 and 10.015, which elaborate upon Principle VIII, describe the fundamental character of an ongoing physician-patient relationship as a collaborative effort and a "mutually respectful alliance" in which the parties share the responsibility for making health care decisions. Within this relationship, the physician is a fiduciary bound to promote the patient's best interests and advocate for her welfare. This vests the patient with the right to continuity of health care, but the physician may withdraw upon "giving the patient reasonable assistance and sufficient opportunity to make alternative arrangements for care" [3].

Unlike the code's potential-patient provisions, the ongoing physician-patient relationship provisions lack forceful nondiscrimination language. The inconsistency has been noted by the AMA's Council on Ethical and Judicial Affairs. Responding to a query submitted by the Medical Student Section, the Council held that the code does not make clear whether a physician who is already treating a patient can later decline treatment based a religious or moral belief [4]. Refuse-and-refer seems to be the mechanism that most medical ethicists believe strikes the proper balance between the rights of a patient and the rights of a physician. Like the Council on Ethical and Judicial Affairs, bioethicists writing on physician conscience have likewise endorsed refuse-and-refer [5]. One in particular, writing specifically on North Coast, described refuse-and-refer as the proper way to resolve the lawsuit [6].

Corresponding author: Richard F. Storrow, Professor, School of Law, City University of New York, 65-21 Main St., Flushing, NY 11367, USA, Tel: (718) 3404538; Fax: (718) 340-4275; E-mail: richard.storrow@mail.law.cuny.edu

Accepted July 14, 2011; Published July 18, 2011

Citation: Storrow RF (2011) The Ethics of Exclusion in Infertility Care. J Clinic Res Bioeth 2:114. doi:10.4172/2155-9627.1000114

Copyright: (c) 2011 Storrow RF. This is an open-access article distributed unde the terms of the Creative Commons Attribution License, which permits unrestricted use, distribution, and reproduction in any medium, provided the original author and source are credited. 
The lack of congruency between the potential-patient and ongoingphysician-patient-relationship provisions leaves ample room for the argument that it is ethical for religious doctors to provide a procedure to certain patients and also to refer patients they do not wish to serve to other physicians. It is unsurprising, then, that in Benitez's case, medical associations were able to assume opposing ethical positions on the ultimate issue.

Since the most relevant provisions of the Code of Medical Ethics are not specific enough to resolve the question that was raised in Benitez, it is equally unsurprising that the opinion of the California Supreme Court against North Coast made no mention of the medical ethics arguments. This is not to say that medical ethics condones discrimination in ongoing physician-patient relationships. Quite the contrary, one need only consider important background principles found in the Code's preamble, its principles, other Code of Medical Ethics opinions, and AMA policy statements having to do with a physician's duty to respect the law, uphold human rights, and support the principle of non-discrimination in patient care. These more general background principles lend strong support to the argument that North Coast's dismissal of Benitez, even with a referral, was unethical. Having to rely on background principles, however, renders the impression that the AMA's endorsement of non-discrimination remains tepid.

It is disappointing, even perplexing, that the potential-patient provisions of the code contain a ringing endorsement of the nondiscrimination principle but the physician-patient relationship provisions do not. Since physicians have wide latitude to pick and choose between potential patients, this seeming lopsidedness may simply be a reminder that, once commenced, the physician-patient relationship carries with it heavy responsibilities that selecting potential patients does not. But surely non-discrimination is one of these, particularly in the case of a religious physician who should recognize the risk of his commencing treatment of a patient to whose sexual orientation or marital status he is morally opposed.

Many believe it is unfortunate that anti-discrimination laws may place religious doctors in an ethical quandary. But anti-discrimination commitments prevail in such contexts because they do the good work of quelling the kind of breaches of the peace, embarrassment, and humiliation that discrimination breeds. Since anti-discrimination laws only prohibit discriminatory activities in the medical marketplace and leave physicians' religious beliefs and observances unburdened, they are uniquely tailored to promoting access to health care for all with a minimum of inconvenience to physicians.

For the good of the profession and the public, medical societies should more explicitly reject the proposition that religious doctors should be exempt from anti-discrimination laws and free to express their class-based biases in the clinic. Since the Code of Medical Ethics is the "leading source of ethical guidance document for the profession," [7] and since it creates indelible perceptions among the public about whether physicians are free to discriminate, what is needed is nothing short of enshrining the non-discrimination principle in the Code of Medical Ethics itself and making clear that it attaches to each and every phase of the physician-patient relationship. Recognizing that the Code contains "inconsistencies in both terminology and guidance among different Opinions that address similar topics," [7] the Council on Ethical and Judicial Affairs is currently in the midst of a multi-year effort to modernize the Code of Medical Ethics [8]. The goal of this undertaking is "to ensure that the Code continues to provide timely, relevant, cogent guidance for the profession." It is to be hoped that, as a part of this project, the Council will fashion a place of prominence for the principle of non-discrimination.

\section{References}

1. Benitez v (2008) North Coast Women's Care Group, 189 P.3d 959.

2. American Medical Association, Code of Medical Ethics Opinion 8.11.

3. American Medical Association, Code of Medical Ethics Opinion 10.01.

4. American Medical Association, Council on Ethical and Judicial Affairs (2007) Physician Objective to Treatment and Individual Patient Discrimination, Rep 6-A-07.

5. Savulescu J (2006) Conscientious Objection in Medicine. Br Med J 332: 294297. Asch A (2006) Two Cheers for Conscience Exceptions. Hastings Cent Rep 36: 11-12.

6. Appel JM (2006) May Doctors Refuse Infertility Treatments to Gay Patients? Hastings Cent Rep 36: 20-21

7. American Medical Association, Council on Ethical and Judicial Affairs (2008) Modernizing the AMA Code of Medical Ethics, Rep 5-I-08.

8. American Medical Association, Council on Ethical and Judicial Affairs (2010) Update: Modernizing the AMA Code of Medical Ethics, Rep 9-I-10. 